\title{
Procesos y factores de exclusión social en las historias de vida de las mujeres institucionalizadas en centros de protección de la Comunidad Valenciana
}

\section{Gabriela Moriana Mateo}

Departament de Treball Social i Serveis Socials, Institut Universitari d'Estudis de la Dona, Univesitat de València

<gabriela.moriana@uv.es>

Artikulu honetan aurkezten da Valentziako Erkidegoko emakumeentzako harrera-zentro batzuen inguruan eginiko landa-lan etnografiko batean bildutako emaitzen lehenengo zatia. Bere xedea da instituzio horietan dauden emakumeen bizitzaldien azpiko gizarte-bazterketa prozesu eta faktoreak aztertzea. Kualitatiboak izan dira betekizun horretarako erabili izan diren ikerketa-teknikak. Bertan burutu dira behaketa parte-hartzaile eta elkarrizketa biografikoak, eta dokumentu pertsonal eta txosten sozialak erabiliz, osatu dira bizitzaldiko hamabost historia; baina hurbilketa honetan kontuan hartu dira horietatik sei, hau da, bizitzaren hasieran kalteberatasuna ezaugarri izandako emakume horien historiak. Emaitzei dagokionez, nabarmendu behar da aipatutako historia horien guztiet azpian daudela gizarte-bazterketaren inguruko faktoreak, eta gehienbat -edo soilikemakumeei eragiten dietela, eta horren ondorioz izendatu ditugu generoaren berariazko faktore sozial gisara, eta berauen artetik nabarmentzen dira familiaren baitako indarkeria eta genero-indarkeria.

\section{GAKO-HITZAK:}

Emakumeentzako harrera-zentroak, gizartebazterketa, kalteberatasuna, familiaren baitako indarkeria, genero-indarkeria
Este artículo presenta parte de los resultados de un trabajo de campo etnográfico realizado en distintos centros de protección de mujeres de la Comunidad Valenciana. Su objetivo es analizar los procesos y factores de exclusión social que subyacen en las historias de vida de las mujeres institucionalizadas. Las técnicas de investigación utilizadas han sido cualitativas. Se ha realizado observación participante y entrevistas biográficas, que junto con documentos personales e informes sociales, han permitido elaborar quince historias de vida, aunque en esta aproximación sólo se analizan seis, las de las mujeres que iniciaron su trayectoria vital en el espacio de vulnerabilidad. Respecto a los resultados, cabe señalar que, en las mencionadas historias, subyacen factores de exclusión social que afectan, sobre todo -o únicamente- a las mujeres, por lo que los hemos denominado factores de exclusión social específicos de género, entre los cuales destacan la violencia intrafamiliar y de género.

\section{Palabras Clave:}

Centros de acogida de mujeres, exclusión social, vulnerabilidad, violencia intrafamiliar, violencia de género. 


\section{Introducción}

Este artículo recoge parte de los resultados de un trabajo de campo realizado en distintos centros residenciales de los servicios sociales especializados para mujeres de la Generalitat Valenciana. Su objetivo es conocer los procesos y factores de exclusión social que subyacen en las historias de vida de las mujeres mayores de edad institucionalizadas en los mencionados centros de protección que iniciaron su trayectoria vital en la situación de vulnerabilidad, desde su punto de vista y desde la perspectiva de género. Como apunta Brunet (2009), si nos aproximamos al estudio de la exclusión sin tener en cuenta la categoría de género, no seremos capaces de estimar la incidencia real, ni mucho menos conocer, los principales factores que la provocan.

La denominación de los centros residenciales de servicios sociales especializados para mujeres de la Generalitat Valenciana ha ido cambiando a lo largo del tiempo. La primera tipología ${ }^{1}$ diferenciaba entre casa de acogida para mujeres en situación de emergencia y residencia materno infantil; la segunda ${ }^{2}$, entre casa de acogida para mujeres en situación de emergencia, centros de acogida y pisos tutelados. Finalmente, de acuerdo con la actual la Ley $7 / 2012$, de 23 de noviembre, Integral contra la Violencia sobre la Mujer en el Ámbito de la Comunidad Valenciana, la red de asistencia social integral a las víctimas de violencia sobre la mujer queda constituida por los siguientes servicios de régimen residencial:

- Centros de emergencia: son recursos especializados de corta estancia que ofrecen acogida inmediata a las mujeres y menores que las acompañan. En ellos se proporciona alojamiento, manutención, protección, apoyo e intervención psicosocial especializada.

- Centros de recuperación integral: están especializados en la atención integral a las mujeres víctimas de violencia y a los menores que las acompañan que necesitan de un alojamiento temporal más prolongado, debido a los malos tratos sufridos, a la falta de apoyo familiar y a la ausencia de recursos personales. La estancia incluirá prestaciones de alojamiento, manutención, protección, apoyo e intervención psicosocial.

${ }^{1}$ Orden de 9 de abril de 1990 , de la Conselleria de Trabajo y Seguridad Social, por la que se desarrolla el Decreto 40/1990, de 26 de febrero, del Consell de la Generalitat Valenciana, sobre Registro, Autorización y Acreditación de los Servicios Sociales de la Comunidad Valenciana.

${ }^{2}$ Orden de 17 febrero de 2003 , de la Conselleria de Bienestar Social, sobre condiciones y requisitos para la autorización de los Centros Especializados para mujeres en situación de riesgo social, por la que se desarrolla el Decreto 91/2002, de 30 de mayo, del Gobierno Valenciano, sobre Registro de los Titulares de Actividades de Acción Social, y de Registro y Autorización de Funcionamiento de los Servicios y Centros de Acción Social, en la Comunidad Valenciana.
- Viviendas tuteladas: son hogares para mujeres víctimas de violencia que necesitan protección y tienen un nivel de autonomía personal que les permita vivir en ellos de forma autogestionada.

\section{Material y método}

Tanto la metodología de investigación como las principales técnicas utilizadas en este trabajo han sido de índole cualitativa. Se ha realizado observación participante ${ }^{3}$, análisis documental (de informes sociales y otros documentos personales) y, sobre todo, entrevistas informales y en profundidad, pasando de la entrevista como técnica a las historias de vida como estrategia. En este sentido, cabe decir que, en puridad metodología, no se puede hablar de selección de casos, sino más bien de intentos continuados de obtener información de las residentes. Es muy difícil que hablen, hay mucho dolor, no conocen a las profesionales y desconfían de la institución; por eso, se trata de una información dificilísima de conseguir y de un valor inconmensurable.

Como resultado del trabajo de campo, se han podido elaborar quince historias de vida de mujeres en procesos de exclusión social que han residido en los centros de protección de la Comunidad Valenciana entre 1999 y 2012, aunque debido a los límites de este artículo sólo se van a analizar las que corresponden a las mujeres que iniciaron el proceso o trayectoria vital en el espacio o zona de vulnerabilidad, pero sólo a partir de los 18 años, es decir, desde su mayoría de edad legal.

El concepto de exclusión social es objeto de diversas definiciones y ha sido profusamente abordado desde las ciencias sociales (Tezanos, 1999; Estivill, 2003; Raya, 2006; Laparra et al. 2007; Laparra y Pérez Eransus, 2008). Para este acercamiento, se han revisado algunas de las principales aportaciones con el objetivo de entender los procesos de exclusión social que subyacen en las historias de vida analizadas.

Para Unicef (2005), la exclusión social incluye privación, entre otros, de los derechos económicos, sociales y políticos. Tezanos (1999) define la exclusión social en sentido negativo, en términos de aquello de lo que se carece. Se trata de un fenómeno con tres aspectos clave: su origen estructural, su carácter multidimensional y su naturaleza procesual (Cabrera, 1998; Tezanos, 1999; Subirats, 2004, 2005; Raya, 2006; Laparra et al., 2007; Hernández Pedreño, 2008; Uceda, 2011; Moriana, 2014).

La exclusión social es un fenómeno estructural (Tezanos, 1999; Ministerio de Trabajo y Asuntos Sociales, 2001; Bel Adell, 2002; Subirats y Gomà,

${ }^{3}$ En los centros de protección en los que la investigadora era una profesional asalariada, lo que convertía al espacio profesional en objeto de investigación. 
2003; Gabàs, 2003; Subirats, 2005; Cabrera, 2005; Raya, 2006; Laparra et al., 2007; Enríquez, 2007; Moriña, 2007; Jiménez Ramírez, 2008; Hernández Pedreño, 2010; Uceda, 2011; Moriana, 2014) y multidimensional (Juárez y Renes, 1995; Atkinson, 1998; Tezanos, 1999 y 2001; Brugué, Gomà y Subirats, 2002; Gabàs, 2003; Subirats, 2004, 2005; Cabrera, 2005; Raya, 2006; Moriña, 2007; Laparra et al., 2007; Laparra y Pérez Eransus, 2008; Jiménez Ramírez, 2008; Hernández Pedreño, 2008; Hernández Pedreño, 2010; Uceda, 2011; Moriana, 2014).

Para Tezanos (1999), más allá del ámbito económico, el fenómeno de la exclusión social se despliega sobre las dimensiones laboral, cultural, personal y social, y a cada una de ellas le corresponden una serie de factores de integración y de exclusión. Laparra et al. (2007) realizan una clasificación que incluye las dificultades o barreras en al menos tres dimensiones: participación económica (pobreza económica), participación social (aislamiento social, conflictividad familiar y otros factores) y participación política (entendida como el acceso limitado a los sistemas de protección social, sanidad, vivienda, educación o prestaciones sociales).

Subirats et al. (2004) proponen una perspectiva integral de exclusión social que incluye siete ámbitos o dimensiones -económica, laboral, formativa, residencial, relacional, ciudadanía y participación-, precisando además una serie de factores de exclusión para cada una ellas. Así, cada una de las referidas dimensiones de exclusión estaría, a su vez, influida por tres ejes de desigualdad social: género, edad, y origen o etnia. Según estos autores/as, las mujeres, al igual que los jóvenes o ancianos, poseen factores de exclusión específicos, determinados por su propia posición en el sistema social. En los factores de exclusión social específicos de género se centra este trabajo.

También existe consenso en considerar la exclusión social como un proceso dinámico (Castel, 1997 y
2004; Atkinson, 1998; Tezanos, 1999; Castells, 2001; Bel Adell, 2002; Estivill, 2003; Gabàs, 2003; Subirats, 2004, 2005; Cabrera, 2005; Raya, 2006; Laparra et al., 2007; Moriña, 2007; Hernández Pedreño, 2010; Uceda, 2011; Damonti, 2014; Moriana, 2014), en el que, siguiendo planteamientos como los de Castel (1997), se pueden distinguir tres espacios o zonas: de integración, de vulnerabilidad y de exclusión social. Así, y a pesar de las dificultades que supone ceñir las complejas realidades de la exclusión social a categorizaciones preestablecidas y dado que todas las historias de vida que se recogen en este trabajo finalizan en la zona de exclusión/institucionalización, se han clasificado según el punto de partida de la trayectoria en los mencionados espacios en función de dos de los ejes clásicos de integración-exclusión: los ingresos económicos (bien procedan del trabajo remunerado o de distintos tipos de prestaciones sociales) y la capacidad integradora de las redes sociofamiliares.

Siguiendo estos planteamientos, las trayectorias vitales de las mujeres en procesos de exclusión social institucionalizadas en los centros de protección de mujeres de la Comunidad Valenciana se inician en la zona de integración social (trabajo remunerado estable y relaciones familiares sólidas), vulnerabilidad (trabajo remunerado irregular o prestaciones sociales; y relaciones familiares débiles, conflictivas y violentas) y exclusión social (trabajo remunerado muy irregular o inexistente, o dependencia de las prestaciones sociales; y relaciones familiares inexistentes, conflictivas 0 violentas). En el Cuadro 1, se sintetizan las variables utilizadas para clasificar las historias de vida en los mencionados espacios.

Así, se diferenciará entre las tres trayectorias vitales que se inician en la situación de integración social, las ocho que lo hacen en un punto intermedio o de vulnerabilidad, y las cuatro que habitan de forma invariable en el espacio de exclusión social, como se puede ver en el Cuadro 2.

\begin{tabular}{|l|l|l|l|l|}
\hline \multicolumn{6}{|l|}{ Cuadro 1. Integración, vulnerabilidad y exclusión social en las relaciones de género } \\
\hline Familia & Ejes & Integración & Vulnerabilidad & Exclusión \\
\hline \multirow{2}{*}{ Origen } & $\begin{array}{l}\text { Ingresos } \\
\text { económicos }\end{array}$ & $\begin{array}{l}\text { Trabajo remunerado } \\
\text { estable }\end{array}$ & $\begin{array}{l}\text { - Trabajo remunerado irregular. } \\
\text { Prestaciones económicas de los } \\
\text { servicios sociales. }\end{array}$ & $\begin{array}{l}\text { - Trabajo remunerado muy irregular o } \\
\text { inexistente. } \\
\text { • Prestaciones económicas de los } \\
\text { servicios sociales. }\end{array}$ \\
\cline { 2 - 5 } & Redes familiares & Sólidas & • Débiles, conflictivas y violentas. & • Conflictivas, violentas o inexistentes. \\
\hline
\end{tabular}

Fuente: Elaboración propia.

\begin{tabular}{|c|c|c|c|}
\hline Inclusión & \multicolumn{2}{|c|}{ Vulnerabilidad } & Exclusión \\
\hline $\begin{array}{l}\text { Reme (HV6) } \\
\text { Loli (HV8) } \\
\text { Marian (HV15) }\end{array}$ & $\begin{array}{l}\text { Maite }\left(\mathrm{HV}_{1}\right) \\
\text { Lola }\left(\mathrm{HV}_{2}\right) \\
\text { Teresa }\left(\mathrm{HV}_{4}\right) \\
\text { Belén }\left(\mathrm{HV}_{5}\right)\end{array}$ & $\begin{array}{c}\text { Concha }\left(\mathrm{HV}_{9}\right) \\
\text { Carmina }\left(\mathrm{HV}_{10}\right) \\
\text { Mayte }\left(\mathrm{HV}_{13}\right) \\
\text { Lorena }\left(\mathrm{HV}_{14}\right)\end{array}$ & $\begin{array}{c}\text { Sonia }\left(\mathrm{HV}_{3}\right) \\
\text { Karmela }\left(\mathrm{HV}_{7}\right) \\
\text { Dolores }\left(\mathrm{HV}_{11}\right) \\
\text { Gracia }\left(\mathrm{HV}_{12}\right)\end{array}$ \\
\hline
\end{tabular}

* Los nombres son ficticios, por motivos de confidencialidad.

Fuente: Elaboración propia. 
Sin embargo, como ya se ha señalado, el presente análisis se ha centrado en las seis trayectorias vitales de las mujeres institucionalizadas cuyo proceso se inicia en la situación de vulnerabilidad, a partir de su mayoría de edad legal (en realidad, son ocho; dos de ellas, aunque madres -y por eso están en un centro residencial de mujeres- son menores de edad en el periodo de institucionalización y, por lo tanto, de recogida de la información para elaborar las historias de vida).

\section{Resultados}

De las seis historias de vida analizadas en este artículo, cuatro mujeres transitan de la vulnerabilidad a la exclusión social siendo ya mayores de edad y dos ya están en la situación de exclusión cuando llegan a la mayoría de edad. Vamos a ver la imagen gráfica del proceso y la valoración de la trayectoria vital.

\subsection{Trayectoria vital adulta desde la vulnerabilidad a la exclusión social}

\begin{tabular}{|l|}
\hline $\begin{array}{l}\text { Figura 1. Trayectoria vital desde la vulnerabilidad a la } \\
\text { exclusión social }\end{array}$ \\
\hline Integración \\
\hline Vulnerabilidad \\
\hline Exclusión \\
\hline \\
Fuente: Elaboración propia.
\end{tabular}

\subsubsection{Maite (nacida en 1974, en una capital andaluza)}

VULNERABILIDAD: HASTA LOS 26 AÑOS

Sale de casa sin tener a dónde ir, cuando cumple 18 años, a causa del incesto o violencia sexual que su padre ejercía contra ella. La acoge la madre del chico con el que acaba de iniciar una relación. La madre de su ya pareja les proporciona casa y los recursos económicos necesarios, porque ni su marido ni ella tienen trabajo remunerado (su compañero, porque no quiere trabajar; y ella, porque además de los continuos embarazos, enferma de vesícula). Maite realiza todo el trabajo no remunerado (tanto las tareas domésticas como el cuidado de sus dos hijas e hijo). Las relaciones son conflictivas y violentas, y Maite sufre violencia de género física, psíquica y sexual.

\section{EXCLUSIÓN SOCIAL: A PARTIR DE LOS 26 AÑOS}

Denuncia a su pareja y tiene que dejar el domicilio conyugal. Como no cuenta con recursos económicos propios ni redes sociofamiliares que la acojan, tiene que ser ingresada en un centro de protección, junto con sus dos hijas (de 4 y 2 años) e hijo (de 7 meses), por los cuales nunca ha cobrado pensión de alimentos.

\subsubsection{Teresa (nacida en 1978 , en una ciudad cercana a València)}

VULNERABILIDAD: HASTA LOS 21 AÑOS

Su trayectoria vital adulta se inicia en el espacio de vulnerabilidad, porque su padre, único proveedor de los recursos económicos de su familia de origen, maltrata físicamente tanto a su madre como a ella. Con 19 años, inicia una relación, y su pareja la maltrata física, psíquica y sexualmente (la deja embarazada de forma premeditada), por lo que rompe la relación y, con 20 años, tiene a su primer bebé (al que el padre no reconoce). Sigue viviendo en casa de su familia de origen hasta que, poco después, fallece su madre, momento en el que abandona el hogar paterno sin tener a dónde ir.

\section{EXCLUSIÓN SOCIAL: A PARTIR DE LOS 22 AÑOS}

Duerme con el bebé en casa de una amiga o en la calle, cuando no hay suerte. Inicia una nueva relación; su pareja procede de una familia marginal. Los servicios sociales decretan una situación de desamparo, declaran una tutela automática y le retiran al bebé. Se vuelve a quedar embarazada; esta vez es un bebé deseado por ella y, como no puede seguir viviendo en la calle, es ingresada en un piso tutelado de su pueblo. Una vez en el centro, incumple horarios y normas, y lleva a dormir a su pareja con ella. Se trata de una falta grave, por lo que es expulsada, pero como está en avanzado estado de gestación y no la pueden dejar en la calle, la ingresan en otro centro de protección de la capital. Dado que está en un ambiente protegido, le dejan tener con ella al bebé que le habían retirado. Incumple normas y horarios, y es denunciada por malos tratos contra su hijo durante una salida del centro, por lo que le vuelven a retirar al menor, pero sigue en la institución, debido a su estado de gestación. Tiene pocos hábitos y habilidades sociales, carece de formación y no ha trabajado nunca fuera de casa, por lo que su salida autónoma del centro con su nuevo bebé es prácticamente imposible.

\subsubsection{Mayte (nacida en 1976, en Rumanía)}

\section{VULNERABILIDAD: HASTA LOS 26 AÑOS}

Hasta los 19 años, vive con su familia de origen en una situación de vulnerabilidad, ya que su padre maltrataba a su madre. A esa edad, conoce a un chico y deja su trabajo remunerado para irse a vivir con él. Muy pronto, se inicia la violencia de género, sobre todo, malos tratos psicológicos. Además, su compañero tiene importantes problemas de ludopatía. A los 23 años, Mayte 
tiene a su primera hija y se separa; el padre no asume responsabilidad alguna (ni de cuidados ni económica) respecto a niña. Posteriormente, Mayte inicia una nueva relación de pareja (él es de religión musulmana), se vuelve a quedar embarazada y se va a vivir a la casa de sus padres de su compañero. Aunque ella no quiere, él emigra al Estado español y Mayte aborta de forma espontánea. Poco tiempo después, ella se reúne con él y se vuelve a quedar embarazada. Una vez en el Estado español, su pareja la maltrata física, psíquica y económicamente, y cuando ella no puede aguantar más la situación (aunque no quería, pues se trata del padre de su futuro bebé), le denuncia. Como no tiene recursos económicos propios, ni trabajo remunerado, ni dónde vivir, la derivan al Centro Mujer 24 Horas, desde donde se formaliza un ingreso urgente en casa de acogida.

\section{EXCLUSIÓN SOCIAL: A PARTIR DE LOS 26 AÑOS}

Ingreso en casa de acogida en avanzado estado de gestación y situación documental irregular.

\subsubsection{Lorena (nacida en 1981, en Colombia)}

\section{VULNERABILIDAD: HASTA LOS 30 AÑOS}

Su pareja va a emigrar desde Colombia a Costa Rica con su familia, y ella se queda embarazada para irse con él, dejando estudios y familia. A los 19 años, nace su primer hijo. Su compañero presenta una importante adicción al alcohol y no aporta dinero a la economía doméstica, ni se ocupa de su hijo. A la violencia de género económica, se suma la violencia psicológica. Cuando el niño tiene un año y medio, Lorena regresa a Colombia con su madre; su pareja no le pasa pensión de alimentos y jamás vuelve a intentar verles. Una vez en Colombia, su madre la ayuda con el bebé, y Lorena encuentra trabajo remunerado e inicia una nueva relación. Su nuevo compañero la deja embarazada de forma premeditada y posteriormente desaparece y nunca ve a su hijo, ni se ocupa de ningún aspecto relacionado con él. Posteriormente, a través del chat, conoce a un hombre español, con el que poco después se casa. El ya marido de Lorena regresa a España, mientras ella se queda en Colombia hasta que su permiso de residencia por reagrupación familiar y el de sus hijos esté en regla. Al año, aproximadamente, Lorena llega al Estado español con sus dos hijos, uno de 5 años y otro de 2. Una vez aquí, se tiene que ocupar de cinco menores (tres de su pareja y dos de ella) y también tiene que realizar la limpieza del bar de su pareja, sin ningún tipo de remuneración económica. El marido de Lorena ejerce todo tipo de violencia contra ella (malos tratos físicos, sexuales, psíquicos y económicos), que hace extensivos contra sus dos hijos, sobre todo, los físicos y psíquicos. Después de que su pareja le propinase una paliza, Lorena decide marcharse con sus hijos; no sabe qué hacer y llama al 091 para que la ayuden. La derivan al Centro Mujer 24 Horas, desde donde valoran la pertinencia de su ingreso en centro de acogida, tras interponer denuncia, dado que no tiene recursos personales propios, ni dónde vivir.

\section{EXCLUSIÓN SOCIAL: A PARTIR DE LOS 30 AÑOS}

Lorena ingresa en el centro de acogida con sus dos hijos (uno de 11 años y otro de 8).

\subsection{Trayectoria vital adulta en la situación de exclusión social}

\begin{tabular}{|l|}
\hline $\begin{array}{l}\text { Figura 2. Trayectoria vital de forma permanente en la } \\
\text { exclusión social }\end{array}$ \\
\hline \\
\hline Integración \\
\hline Vulnerabilidad \\
\hline Exclusión \\
\hline \\
\hline Fuente: Elaboración propia.
\end{tabular}

\subsubsection{Lola (nacida en 1977 , en Valencia)}

\section{EXCLUSIÓN SOCIAL: DESDE LOS 18 HASTA LOS 22 AÑOS}

Sufre malos tratos, aunque también físicos, sobre todo, económicos, por parte de su pareja, con quien inicia la convivencia cuando sale de casa de forma precipitada al cumplir 18 años, debido a los abusos sexuales a los que la sometía su padrastro. No tienen dónde vivir, por lo que lo hacen con familiares y personas conocidas, pero también en la calle. Asimismo, ocupan casas tanto en Valencia como en otras ciudades a las que van buscando empleo. Su pareja nunca trabaja; ella realiza trabajos remunerados precarios muy irregulares, hasta que se queda embarazada. Dada la situación, poco antes de dar a luz solicita ayuda a los servicios sociales, que, atendiendo a su avanzado estado de gestación, la derivan a una residencia de mujeres. Allí nace su primera hija; Lola tiene 19 años. Cuando se recupera del parto, con el pretexto de que ha encontrado trabajo, se marcha del centro con su bebé. A los pocos meses, se vuelve a quedar encinta. Su pareja sigue sin trabajar, ni participar en la atención y cuidado de la niña. Aunque con muchas contradicciones, porque no quiere volver a vivir en una institución, y dado que no tiene dónde hacerlo, Lola vuelve a solicitar ingreso en centro de mujeres y nace su segunda hija. Tanto la estancia en la residencia como la posterior salida son muy complicadas, ya que Lola tiene problemas de salud mental, escasa formación y habilidades sociolaborales, ningún tipo de apoyo sociofamiliar y dos niñas muy pequeñas a su cargo en solitario. 


\subsubsection{Carmina (nacida en 1970, en un pueblo de la provincia de Castellón)}

EXCLUSIÓN SOCIAL: DURANTE TODA SU TRAYECTORIA VITAL ADULTA

A los 18 años, ya vive con su pareja y sufre malos tratos físicos, psíquicos, sexuales y económicos por parte de su compañero. Viven en un vertedero, sin agua ni luz. A los 21 años, nace su primer hijo, y a los 24 , tiene una hija, y dadas las dificultades de los dos partos, le realizan una ligadura de trompas. Ella tenía que ocuparse de todas las tareas de cuidados de los dos menores, e incluso de hacerle los porros a su pareja. Tras una importante paliza en público, que posteriormente continua en su casa, un vecino que no quiere identificarse avisa a la Policía, que acude al domicilio y arresta a la pareja de Carmina. A la mañana siguiente, la ingresan en la casa de acogida por malos tratos físicos e intento de asesinato por parte de su pareja; tiene 29 años, un hijo de 8 y una hija de 5 , y ha roto prácticamente toda la relación con su familia biológica. Antes del mes de estar en el centro, se marcha con el agresor. Los malos tratos siguen y Carmina solicita un nuevo ingreso en casa de acogida, pero fuera de la provincia. Vuelve a ingresar en el centro de protección de mujeres, donde se desespera, pues el tiempo pasa y no encuentra trabajo (no tiene formación, ni experiencia laboral), y dice que, para que le quiten a sus hijos, prefiere aguantar los malos tratos y verles crecer a su lado.

\section{Discusión y conclusiones}

De acuerdo con el objetivo planteado, se van a abordar, en primer lugar, los principales rasgos del proceso de exclusión social, y seguidamente, los factores de exclusión social más importantes que subyacen en las historias de vida de las mujeres institucionalizadas en centros de acogida cuya trayectoria vital se inicia en el espacio de vulnerabilidad a partir de su mayoría de edad legal.

En primer lugar, y respecto al proceso de exclusión social, como hemos podido observar, cuatro de las seis mujeres transitan al espacio o zona de exclusión social cuando son mayores de edad y las otras dos lo hacen siendo todavía menores, por lo que su trayectoria de vida adulta se desarrolla en la zona de exclusión social de forma permanente.

Siguiendo con el proceso de exclusión social y en relación con las primeras trayectorias, cabe señalar que las redes familiares coadyuvan a mantener retrasando el tránsito a la zona de exclusión social: es el caso de la suegra que proporciona a la unidad familiar de su nuera, hijo y descendencia casa e ingresos económicos; de los padres que acogen a su hija marido y nieta cuando no tienen ingresos económicos ni dónde vivir; y también de la madre que ampara a nieto e hija cuando rompe la relación de pareja.

En ambos modelos de trayectorias, se observa cómo los maridos y padres de las/os hijas/os de las protagonistas no cumplen con el rol de proveedores de la economía doméstica cuando hay convivencia, ni con la obligación de pagar la pensión de alimentos cuando deja de haberla o no la ha habido nunca, al igual que pasaba en las trayectorias vitales de las mujeres institucionalizadas que iniciaban su trayectoria en el espacio de integración (Moriana, 2014). Siguiendo a Espinar (2003), el abandono de estas responsabilidades está estrechamente ligado a la violencia económica, en general, podría considerarse una forma de violencia psicológica y supone la asunción en solitario de las cargas familiares por parte de las mujeres. Pero además, la violencia de género se hace omnipresente; las mujeres de ambas trayectorias sufren todo tipo de malos tratos: físicos, psíquicos, sexuales y económicos. En ocasiones, la violencia, sobre todo física y psicológica, también se hace extensible a sus hijas/os.

Algunos de los maridos presentan adicciones, sobre todo al alcohol, aunque en unos casos maltratan físicamente a sus compañeras, y en otros, no. Asimismo, y rompiendo el mito de la relación alcoholviolencia, también aparece el caso del agresor que no tiene conducta adictiva alguna. El consumo de alcohol o de drogas puede favorecer la emergencia de conductas violentas, pero no las causa; de hecho existe violencia sin drogadicción y drogadicción sin violencia (Echeburúa y De Corral, 1998; Villavicencio y Batista, 1992; Walker, 1979).

Por su parte, ante las situaciones de violencia, como hemos podido advertir, las mujeres actúan y denuncian a los agresores (aunque en ocasiones, no lo querían hacer, porque se trata del padre de sus hijas/os). Como es sabido, las denuncias por violencia de género representan la punta del iceberg. Según la Macroencuesta de Violencia contra la Mujer (Delegación del Gobierno para la Violencia de Género, 2015), siete de cada diez mujeres que han sufrido violencia de género (el 67,8\%) nunca lo han denunciado. Conviene tener en cuenta que nuestras protagonistas necesitan apoyo y ayuda, y de hecho, la piden a ONG, servicios sociales, a la Policía y al Centro Mujer 24 Horas. Tradicionalmente y hasta la implementación de la Ley Integral, estos servicios sólo podían ofrecer a las mujeres maltratadas el ingreso en un centro de protección. Desde entonces hasta la actualidad, existen más tipos de apoyo, tanto para las mujeres españolas como para las extranjeras.

El tránsito a la situación de exclusión social de la mayoría de estas mujeres que inician su trayectoria biográfica en la zona de vulnerabilidad se produce por la salida del hogar conyugal sin tener a dónde ir a causa de la violencia de género, y coincide con 
la institucionalización. Siguiendo a Subirats et al. (2004), para evitar las situaciones de violencia doméstica, a las mujeres se las separa bruscamente de su entorno más inmediato mediante su ingreso en hogares colectivos. Pero los efectos de esa drástica solución desvinculan a las mujeres de dos ejes básicos de integración social: la esfera productiva (su relación con el mercado), en caso de tenerla; y las redes sociales y comunitarias.

Como hemos visto, en los centros de protección también ingresan por violencia de género mujeres que ya estaban en situaciones de exclusión social, pero también las que no tienen dónde vivir (habían salido de la casa de la familia de origen por distintos tipos de violencia intrafamiliar contra las mujeres, sobre todo, sexual y física), debido a los embarazos o cargas familiares. Consecuentemente, en los centros de protección de mujeres conviven las que han ingresado a causa de la violencia de género con aquellas que lo han hecho por motivos relacionados con la exclusión social.

De esta manera, junto con la violencia intrafamiliar, la violencia de género deviene el factor de exclusión social más importante entre las mujeres que inician sus procesos vitales en el espacio de vulnerabilidad, al igual que entre las trayectorias vitales de las mujeres institucionalizadas que iniciaban su trayectoria en la situación de integración (Moriana, 2014). En este sentido, en su Propuesta de indicadores para medir los efectos de la violencia de género en el ámbito de pareja sobre la vida de las mujeres, Camarasa et al. (2009) también afirman que las mujeres que sufren la agresión machista tiene más riesgo de padecer exclusión social, precariedad económica y desempleo.

Sin embargo, aunque no tienen alternativa posible, algunas mujeres manifiestan importantes contradicciones respecto a su ingreso en los centros de acogida, pues en ellos están obligadas a cumplir normas, horarios y a convivir con las demás compañeras, en situaciones igual de complicadas. Como ellas mismas manifiestan, adaptarse a la institución les cuesta mucho. Pero además de perder su intimidad (en algunos centros, la precariedad es tal que hasta tienen que compartir habitación con otras mujeres e hijas/os), en los centros van a estar controladas, en todo momento, por las profesionales.

Así, ante las dificultades, ante la imposibilidad de encontrar un trabajo remunerado y ante el miedo a que les quiten a sus hijas/os, dicen estar dispuestas a aguantar la violencia para poder verlos crecer a su lado. De hecho, en ocasiones abandonan el medio residencial para volver con sus parejas, porque les creen cuando les aseguran que han cambiado y que no las van a volver a pegar. Algunas de las mujeres que llegan a la institución presentan una importante carencia de hábitos y habilidades sociales, debido a sus largas trayectorias de exclusión social, pero también problemas de salud mental a causa de los malos tratos (sobre todo, sexuales) sufridos siendo menores, lo que agrava la ya difícil salida del centro. Por ello, ante la falta de posibilidades reales de vida autónoma fuera del espacio institucional, no faltan los casos en los que, cuando finaliza el periodo de estancia, se produce la derivación de las mujeres a otro centro de protección.

Por otra parte, en las trayectorias analizadas subyacen importantes dimensiones de exclusión social, con sus respectivos factores de exclusión, que afectan tanto a los hombres como a las mujeres: carencia de redes sociales y familiares, falta de formación, ausencia de experiencia laboral y de trabajo remunerado, ingresos económicos insuficientes, adicciones, ludopatías, infravivienda o falta de vivienda, entre otras. Sin embargo, cuando se tiene en cuenta la perspectiva de género y se analiza la realidad de las mujeres en los procesos de exclusión social, se ve claramente, que ellas presentan, como ya ha indicado Damonti (2014), mayores niveles de exclusión en todas las dimensiones. Además, en las trayectorias analizadas subyacen importantes dimensiones y factores de exclusión social que afectan sobre todo -0 únicamente- a las mujeres, por lo que los hemos denominado factores de exclusión social específicos de género.

En este sentido y en referencia a las relaciones familiares, aunque la ausencia, el deterioro, el aislamiento, los conflictos o las relaciones violentas pueden afectar tanto a las mujeres como a los hombres, la violencia intrafamiliar contra las mujeres y de género, la pérdida de redes sociales y familiares de ayuda en las situaciones de violencia de género y los malos tratos contra sus hijas/os (que las obligan a abandonar el hogar de su familia de origen sin tener dónde ir) son factores de exclusión social específicos de género que subyacen en las historias de vida de las mujeres institucionalizadas que inician sus trayectorias vitales en el espacio de vulnerabilidad, al igual que las de quienes inician sus trayectorias vitales en el espacio social de integración (Moriana, 2014).

Respecto al ámbito laboral, si bien el desempleo o la precariedad pueden afectar tanto a las mujeres como a los hombres, las mujeres institucionalizadas cuyas trayectorias se inician en el espacio de la vulnerabilidad, al igual que las que lo hacen en el de la integración (Moriana, 2014), abandonan el empleo para contraer matrimonio y son ellas las que tienen que realizar todo el trabajo no remunerado de sus familias: cuidados (descendencia, familiares de su pareja) y tareas domésticas. Por ello, en ocasiones, ni siquiera se pueden incorporar al trabajo remunerado, por lo que carecen de experiencia profesional, y la que tienen no se valora en el mercado laboral, ya que se trata de aprendizajes adquiridos en el espacio doméstico. Como señala Del Valle (2012), no tiene el mismo valor una tarea realizada en el ámbito doméstico y dentro de las responsabilidades familiares que otra de la misma índole ejecutada en el mercado laboral. Por esa razón, las mujeres que 
nos ocupan no sólo dependen económicamente de sus respectivos compañeros, sino que tienen cerrado el acceso a los derechos laborales y deben pedir ayuda a los servicios sociales.

A ello se suma el incumplimiento del rol de proveedor de la economía doméstica por parte de sus compañeros cuando existe convivencia, y el incumplimiento de la obligación de abonar las pensiones de alimentos cuando no la ha habido nunca, al igual que les pasa a las mujeres institucionalizadas que inician sus trayectorias vitales en el espacio social de integración (Moriana, 2014). También cabe señalar el hecho de que incluso ciertos trabajos remunerados dejan de serlo cuando los realiza la esposa, como es el caso de la limpieza del negocio de su marido sin sueldo ni contrato laboral.

En lo que al ámbito residencial se refiere, tanto los hombres como las mujeres pueden tener una vivienda precaria, o carecer de ella. Además, en el caso que nos ocupa y al igual que las mujeres institucionalizadas que inician sus trayectorias vitales en el espacio de integración social, tienen que irse a vivir a casa de sus suegros o a los lugares donde sus maridos trabajan, y alquilan la vivienda habitual, que posteriormente tienen que dejar cuando sus parejas las abandonan o por las situaciones de violencia de género (Moriana, 2014). A ello se suma aquí el hecho de no tener dónde vivir, motivo por el que los servicios sociales amenazan a las jóvenes con la retirada de su descendencia, que a veces deviene efectiva. Conviene advertir que, aunque, en principio, este factor podría afectar tanto a hombres como a mujeres, lo cierto es que, de facto, los servicios sociales les quitan las/os hijas/os principalmente a las madres. La razón es que son ellas las que se responsabilizan en solitario de las cargas familiares (de cuidado y económicas) o que se trata de madres solas (los padres no han reconocido a su descendencia, o no la conocen, o no cumplen con ningún aspecto del rol de padre), por lo que deviene un factor de exclusión social específico de género.

Por otra parte, cabe señalar otros importantes factores específicos de género de carácter cultural: se trata principalmente de los estereotipos y roles de género, que cumplen una destacada función en la socialización de las mujeres en posiciones subordinadas. En este sentido, Del Valle et al. (2002) apuntan la existencia de aprendizajes específicos que preparan para ejercer el "no poder". Así, la educación de muchas mujeres se realiza en función de las expectativas de los roles de madre y de esposa como elemento prioritario, funciones muy importantes socialmente, pero ni valoradas ni remuneradas.
Pero también, es necesario mencionar a los factores de exclusión social específicos de género que están relacionados con la ausencia de medidas institucionales de apoyo a las mujeres para conseguir la igualdad de oportunidades, como la inexistencia de medidas públicas para que las mujeres puedan conciliar el trabajo remunerado con la vida personal y familiar. En el caso de las mujeres que nos ocupan, la situación se agrava, dada la ausencia de redes sociales y familiares, y la carencia de recursos institucionales de apoyo.

En las trayectorias analizadas, también aparecen factores de exclusión social de género, como la violencia intrafamiliar contra las mujeres, la violencia de género y otros factores relacionados, como los problemas de salud mental a causa de la violencia intrafamiliar sexual. Como señala Ventosa y López (2007), las mujeres han sufrido abuso sexual intrafamiliar en la infancia pueden presentar serios problemas de salud mental en la edad adulta, que van desde el trastorno de angustia a la depresión crónica.

Resta añadir, para finalizar, otro importante factor de exclusión social, que al igual que a nuestras protagonistas, también afecta a las mujeres institucionalizadas cuyas trayectorias se inician en el espacio de integración (Moriana, 2014): la institucionalización en centros de protección de los servicios sociales, tanto por violencia como por exclusión social (sobre todo, debido a embarazos o cargas familiares). Ello puede considerarse un tipo de victimización secundaria, por la privación de ayuda en el ámbito comunitario y la desvinculación de las redes sociales y familiares que conlleva su institucionalización. Porque si bien, en principio, se trata es una medida de apoyo y protección, lo cierto es que las mujeres tienen derecho a ser protegidas y ayudadas fuera del espacio institucional, a ser posible en sus casas, o en viviendas normalizadas. Como hemos visto y también ha señalado Camarasa et al. (2009), debido a la ausencia de recursos institucionales eficaces, muchas mujeres deciden quedarse en sus casas y permanecer con su maltratador, o incluso se ven forzadas a volver con los agresores una vez se han ido. Además, en numerosos casos, cuando tienen que abandonar el centro, se encuentran en la misma la situación que motivó el ingreso.

En el Cuadro 3, se esquematizan los factores de exclusión social específicos de género más importantes que subyacen en las historias de vida de las mujeres que inician trayectoria vital en la situación de vulnerabilidad. 
Cuadro 3. Factores de exclusión social específicos de género que subyacen en las historias de vida de las mujeres que inician la trayectoria vital en situación de vulnerabilidad

- Violencia intrafamiliar contra las mujeres (sexual y física).

- Violencia de género.

- Malos tratos físicos y psíquicos contra sus hijas/os.

- Salida de casa, sin tener dónde ir, a causa de la violencia intrafamiliar sexual contra las mujeres.

- Falta de ayuda de la familia extensa y demás redes sociales en las situaciones de violencia de género.

- Abandono del empleo por contraer matrimonio.

- Realización de todo el trabajo no remunerado de la familia (tareas domésticas y de cuidados).

- Dificultades para compaginar el trabajo productivo y el reproductivo.

- Falta de experiencia laboral o no reconocimiento en el mercado laboral de los aprendizajes realizados en el ámbito doméstico.

- Falta de acceso a derechos laborales.

- Dependencia económica respecto a sus parejas o a los servicios sociales para mantener a su descendencia.

- Incumplimiento del rol de proveedor de la economía doméstica de sus parejas cuando existe convivencia, o impago de pensiones de alimentos cuando no la hay.

- Obligación de trabajar en el negocio del marido sin sueldo ni contrato laboral.

- Abandono del hogar conyugal a causa de la violencia de género.

- Retirada de menores por falta de vivienda.

- Responsabilidad de las cargas familiares en solitario.

- Estereotipos y roles de género.

- Ausencia de medidas de conciliación de la vida laboral y familiar, y carencia de guarderías o centros de día públicos y con amplios horarios.

- Problemas de salud mental a causa de la violencia sexual intrafamiliar contra las mujeres.

- Violencia institucional o victimización secundaria en casos de violencia de género (privación de recursos adecuados en el ámbito comunitario).

- Institucionalización de mujeres en centros de acogida por violencia de género o exclusión social.

Fuente: Elaboración propia. 
ATKINSON, A. B. (1998): "Social exclusion, poverty and unemployment”, en ATKINSON, A. B.; y HILLS, J. (eds.), Exclusion, Employment and Opportunity, serie CASE Papers, $\mathrm{n}^{\circ}{ }_{4}$, Londres, Centre for Analysis of Social Exclusion.

BEL ADELL, C. (2002): "Exclusión social: origen y características", en VV.AA., Formación específica en compensación educativa e intercultural para agentes educativos, Centro de Profesores y Recursos Torre Pacheco.

BRUGUÉ, Q.; GOMÀ, R.; y SUBIRATS, J. (2002): “De la pobreza a la exclusión social. Nuevos retos para las políticas públicas", Revista Internacional de Sociología, $\mathrm{n}$ - 33 , págs. 7- 45.

BRUNET, I. (2009): “Pobreza y exclusión social desde la perspectiva de género", Revista Internacional de Organizaciones, $\mathrm{n}{ }^{\circ}$ 3, págs. 13-21 [rhttp:// dx.doi.org/10.17345/rio3.13-27〉].

CABRERA, P. (dir.) (2005): Nuevas tecnologías y exclusión social Un estudio sobre las posibilidades de las TIC en la lucha por la inclusión social en España, Madrid, Fundación Telefónica.

- (1998): Huéspedes del aire. Sociología de las personas sin hogar en Madrid, Madrid, Universidad Pontificia de Comillas.

CAMARASA, M., et al. (2009): Propuesta de nuevos indicadores para medir los efectos de la violencia de género, Barcelona, Surt Fundació de Dones-Fundació Privada.

CASTEL, R. (2004): “Encuadre de la exclusión”, en KARSZ, S., La exclusión: bordeando sus fronteras. Definiciones y matices, Barcelona, Gedisa.

- (1997): La metamorfosis de la cuestión social. Una crónica del asalariado, Buenos Aires, Paidós.
CASTELLS, M. (2001): La Era de la Información. Fin del milenio, vol. III, México, Siglo XXI.

COMUNIDAD VALENCIANA (2012): “Ley 7/2012, “de 23 de noviembre, de la Generalitat, Integral contra la Violencia sobre la Mujer en el Ámbito de la Comunidad Valenciana", Diari Oficial de la Comunitat Valenciana, no 6.912, 28-11-12, págs. 34.453-34.470 («http://www.docv.gva.es/ portal/ficha_disposicion.jsp?id $=24 \& \operatorname{sig}=0108$ $88 / 2012 \& L=1\rangle$ ).

- (2003): “Orden de 17 febrero de 2003, de la Conselleria de Bienestar Social, sobre condiciones y requisitos para la autorización de los Centros Especializados para mujeres en situación de riesgo social, por la que se desarrolla el Decreto 91/2002, de 30 de mayo, del Gobierno Valenciano, sobre Registro de los Titulares de Actividades de Acción Social, y de Registro y Autorización de Funcionamiento de los Servicios y Centros de Acción Social, en la Comunidad Valenciana", Diari Oficial de la Comunitat Valenciana, nํ⒋942, 9-2-05, págs. 6.070-6.076 («http://www.docv.gva.es/portal/ ficha_disposicion.jsp?sig=0861/2003\&L=1)).

- (1990): “Orden de 9 de abril de 1990, de la Conselleria de Trabajo y Seguridad Social, por la que se desarrolla el Decreto 40/1990, de 26 de febrero, del Consell de la Generalitat Valenciana, sobre Registro, Autorización y Acreditación de los Servicios Sociales de la Comunidad Valenciana", Diari Oficial de la Comunitat Valenciana, $\mathrm{n}$-1.291, 26-4-90 («http://www.docv.gva.es/portal/ficha_ disposicion.jsp?id=24\&sig=0992/1990\&L=1〉).

DAMONTI, P. (2014): “Exclusión social y género: un análisis de la realidad contemporánea”, Zerbitzuan, no- 57, págs. 71-89 [<http://dx.doi. org/10.5569/1134-7147.57.04']. 
DEL VALLE, T. (2012): "Un ensayo metodológico sobre la mirada en la Antropología Social", Gazeta de Antropología, vol. 28, no-10 [khttp://www. gazeta-antropologia.es $/ \mathrm{p}=3987\rangle]$.

DEL VALLE, T. et al. (2002): Modelos emergentes en los sistemas y las relaciones de género, Madrid, Narcea.

DELEGACIÓN DEL GOBIERNO PARA LA VIOLENCIA DE GÉNERO (2015): Macroencuesta de Violencia contra la Mujer. Avance de resultados, Madrid, Ministerio de Sanidad, Servicios Sociales e Igualdad.

ECHEBURÚA, E.; y DE CORRAL, P. (1998): Manual de violencia familiar, Madrid, Siglo XXI.

ENRÍQUEZ, P. G. (2007): “De la marginalidad a la exclusión social: un mapa para recorrer sus conceptos y núcleos problemáticos”, Fundamentos en Humanidades, $\mathrm{n}-1$, págs. 55-88.

ESPINAR, E. (2003): Violencia de género y procesos de empobrecimiento. Estudio de la violencia contra las mujeres por parte de su pareja o expareja sentimental [tesis doctoral], Universidad de Alicante.

ESTIVILL, J. (2003): Panorama de lucha contra la exclusión social: conceptos y estrategias, Ginebra, Oficina Internacional del Trabajo.

GABÀS, Á. (2003): Indicadores de género contra la exclusión social, Surt Asociació de Dones per a la Inserció Laboral.

HERNÁNDEZ PEDREÑO, M. (2010): "El estudio de la pobreza y la exclusión social. Aproximación cuantitativa y cualitativa", Revista Interuniversitaria de Formación del Profesorado, no 69, págs. 25-46.

- (2008): "Pobreza y exclusión social en las sociedades del conocimiento", en HERNÁNDEZ PEDREÑO, M. (coord.), Exclusión social y desigualdad, Murcia, Universidad de Murcia.

JIMÉNEZ RAMÍREZ, M. (2008): “Aproximación teórica de la exclusión social: complejidad e imprecisión del término. Consecuencias para el ámbito educativo", Estudios Pedagógicos (Valdivia), vol. 34, nํㅜ 1, págs. 173-186.

JUÁREZ, M.; y RENES, V. (1995): "Población, estructura y desigualdad social”, Documentación Social, no 101 [monográfico 'V Informe sociológico sobre la situación social en España. Sociedad para todos en el año 2000. Síntesis’], págs. 67-132.

LAPARRA, M.; y PÉREZ ERANSUS, B. (coords.) (2008): “La exclusión social en España: un espacio diverso y disperso en intensa transformación", $V I$ Informe sobre exclusión y desarrollo social en España, Madrid, Fundación Foessa.

LAPARRA, M. et al. (2007): "Una propuesta de consenso sobre el concepto de exclusión. Implicaciones metodológicas", Revista Española del Tercer Sector, $n^{0} 5$, págs. $15-57$.
MINISTERIO DE TRABAJO Y ASUNTOS SOCIALES (2001): Plan Nacional de Acción para la Inclusión Social del Reino de España, Madrid, Ministerio de Trabajo y Asuntos Sociales.

MORIANA, G. (2014): “Entre la exclusión y la violencia. Las mujeres institucionalizadas en los centros de protección de mujeres de la Comunidad Valenciana" [tesis doctoral], Universitat de València, Instituto Universitari d'Estudis de la Dona [<http://roderic.uv.es// handle/10550/35219>].

MORIÑA, A. (2007): La exclusión social: análisis y propuestas para su prevención, Madrid, Fundación Alternativas.

RAYA, E. (2006): Indicadores de exclusión social. Una aproximación al estudio aplicado de la exclusión social, Bilbao, Universidad del País Vasco.

SUBIRATS, J. (dir.) (2005): Análisis de los factores de exclusión social, serie Documentos de Trabajo, nํㅜ 4, Bilbao, Fundación BBVA; Generalitat de Catalunya.

- (2004): Pobreza y exclusión social. Un análisis de la realidad española y europea, serie Colección Estudios Sociales, $\mathrm{n}-16$, Barcelona, Fundación La Caixa [<http://caixaescena. es/deployedfiles/obrasocial/Estaticos/pdf/ Estudios_sociales/vol16_es.pdf)].

SUBIRATS, J.; y GOMÁ, R. (dirs.) (2003): Un paso más hacia la inclusión social. Generación de conocimiento, políticas y prácticas para la inclusión social, Madrid, Plataforma de ONGs de Acción Social.

TEZANOS, J. F. (1999): Tendencias en desigualdad y exclusión social, Madrid, Fundación Sistema.

UCEDA, F. X. (2011): “Adolescentes en conflicto con la ley. Una aproximación comunitaria: trayectorias, escenarios e itinerarios" [tesis doctoral], Universitat de València.

UNICEF (2005): Estado mundial de la infancia 2006. Excluidos e invisibles, Nueva York, Unicef.

VENTOSA, M.; y LÓPEZ, R. (2007): “Perfil clínico e intervención en salud mental con mujeres supervivientes a abuso sexual infantil intrafamiliar (incesto)", en COBO GÓMEZ, J. (coord.), Publicación oficial de la Sociedad Española de Psiquiatría Biológica, vol. 14, nํㅜ 4, pp. 153-162.

VILLAVICENCIO, P.; y BATISTA, N. M. (1992): “Un problema específico de salud en la mujer: la situación de maltrato", Clínica y Salud, no 3 [monográfico 'Mujer y salud mental (I)’], págs. 239-249.

WALKER, L. (1979): The Battered Women, Nueva York, Harper \& Row Publishers [CORDERO, R. M. (trad.), Las mujeres agredidas]. 